\title{
Validity and reliability of a Severity of Dependence Scale for khat (SDS-khat)
}

\author{
Saba Kassim*, Sharif Islam, Ray Croucher \\ Queen Mary University of London, Barts and The London School of Medicine and Dentistry, Institute of Dentistry, 4 Newark Street, London E1 4AT, UK
}

\section{A R T I C L E I N F O}

\section{Article history:}

Received 1 July 2010

Received in revised form 2 September 2010

Accepted 3 September 2010

Available online 15 September 2010

\section{Keywords:}

Khat

Dependence

Construct and concurrent validity

Test-retest reliability

Yemeni

\begin{abstract}
A B S T R A C T
Aims of the study: (1) To assess psychological khat dependence and (2) to assess the validity and reliability of the Severity Dependence Scale (Gossop et al., 1995) amended for khat use (SDS-khat), in a sample of UK-resident male adult Yemeni khat chewers.

Materials and methods: A cross-sectional study using a face to face structured interview schedule was conducted amongst purposively sampled UK-resident adult Yemeni male khat chewers, aged 18 years and above, selected during random visits to places of khat sale. A factor analysis with principal components extraction was conducted to explore the construct validity of the proposed SDS-khat. Reliability of the proposed scale was assessed using test-retest and internal reliability tests. The concurrent validity of the proposed SDS-khat was assessed in relation to individual measures and a composite index of khat chewing behaviours using univariate analyses.

Results: Two hundred and four Yemeni male adult khat chewers were interviewed. The mean score of the proposed SDS-khat was 5.52 (SD \pm 4.03 ). Forty nine percent of respondents $(95 \% \mathrm{CI}=43-55 \%)$ with $\leq 5$ scores were more likely not psychologically dependent. A single factor, uni-dimensional solution identifying the five items making up the scale accounted for 52.33\% of variance. The internal reliability was good (Cronbach's alpha coefficient $=0.76$ ) and the test retest intraclass correlation coefficient $($ ICC) was 0.93 (95\% CI = 0.80-0.97). Many individual aspects of the khat chewing were significantly related to the scale. Assessment of the proposed SDS-khat's concurrent validity with individual items of khat chewing identified several significant relationships $(p \leq 0.05)$ whilst the composite index of khat behaviour also identified a significant relationship ( $\mathrm{OR}=14.40,95 \% \mathrm{CI}=6.71-30.89$ ). The proposed SDS-khat also correlated with self-reported reasons for khat chewing $(p \leq 0.001, \mathrm{OR}=3.54 ; 95 \% \mathrm{CI}=1.80-6.96)$. Conclusions: In this sample of Yemeni khat chewers the SDS-khat is recommended as a valid and reliable research tool for measuring psychological dependence upon khat. Further validation in other samples is indicated.
\end{abstract}

(c) 2010 Elsevier Ireland Ltd. All rights reserved.

\section{Introduction}

Khat is a leaf cultivated and chewed in east Africa and the Arabian Peninsula (Krikorian, 1984). Widespread khat chewing is recognized as an important public health concern (WHO, $2003,2006)$. Khat chewing is reported to facilitate social interaction, improve individual performance and increase work capacity (Halbach, 1972; Kalix and Braenden, 1985; Zein, 1988; Toennes et al., 2003; Al-Habori, 2005). Reported medicinal uses include treating asthma, depression, abating hunger and fatigue and stress (Luqman and Danowski, 1976; Kalix and Braenden, 1985; Rousseau et al., 1998; Nabuzoka and Badhadhe, 2000; Al-Motarreb et al., 2002; Dhaifalah and Santavy, 2004; Freund-Michel et al., 2008; Odenwald, 2009). Unfavourable health, socioeconomic and environmental outcomes have also been associated with frequent khat

\footnotetext{
* Corresponding author. Tel.: +44 0207882 8664/07866103642.

E-mail addresses: s.salam@qmul.ac.uk, saba262003@yahoo.co.uk (S. Kassim).
}

chewing (Ali et al., 2004, 2006; Al-Motarreb et al., 2005; Aden et al., 2006; Kassim and Croucher, 2006; Ali, 2007; Gelaye et al., 2008; FAO, 2008).

The concept of the 'dependence syndrome' that was initially hypothesized for alcohol was based on a physical model that emphasised tolerance and withdrawal (Edwards and Gross, 1976). Nahas (1981) later defined drug dependence/addiction as "A state, psychic and sometimes also physical, resulting from the interaction between a living organism and a drug, characterized by behaviour and other responses that always include compulsion to take the drug on a continuous or periodic basis in order to experience its psychic effects, and sometimes to avoid the discomfort of its absence". Physical and psychological dependence may be distinguished by their symptoms, with withdrawal or tolerance linked to the former and craving and compulsive use to the latter. The concept of 'dependence syndrome' was therefore widened to apply to other psychoactive substances (Edwards et al., 1981). This concept influenced the development of the notion of Substance Dependence in the DSM-IV (American Psychiatric Association, 1994). The essen- 
tial features in this are loss of control over consumption, salience of drug use in the user's life and continuation of use despite knowledge of social and health impacts.

Cathinone in khat resembles amphetamine chemically, both in its physiological and behavioural impacts (Kalix, 1982, 1990; Woolverton and Johanson, 1984; Feyissa and Kelly, 2008). Recognized characteristics of amphetamine use are tolerance and withdrawal symptoms (Nahas, 1981; Churchill et al., 1993; Topp and Darke, 1997; Topp and Mattick, 1997). Tolerance is the necessity to increase a drug dose to retain the initial psychotropic effect (Nahas, 1981). Withdrawal symptoms are the appearance of intense discomfort after suspending drug use (Nahas, 1981). Prolonged or high dose use of psychostimulants such as cocaine and amphetamines can lead to withdrawal symptoms (Gawin and Kleber, 1986) and some, such as sleep disturbance, are reported to be quite prolonged and distressing (Gossop et al., 1982).

The potential for khat chewing to create dependence is contested (Kennedy and Hurwit, 1978; Nencini et al., 1989). Nahas (1981) has proposed that khat is a stimulant more likely creating psychological rather than any physical dependence whilst the UK Advisory Council of Misuse of Drugs (ACMD, 2005) has stated that chewing khat has fewer reinforcing properties than amphetamine and cocaine. The observed tendency of chewers to secure a daily supply of khat at the expense of other needs such as food and their obsessive behaviour in khat markets suggests dependence (Eddy et al., 1965; Nencini and Ahmed, 1989). Mood changes during and after chewing (Luqman and Danowski, 1976; Hassan et al., 2002) were postulated as reinforcing khat chewing (Griffiths et al., 1997; Gelaw and Haile-Amlak, 2004).

Tolerance has been suggested as developing following prolonged hours of khat chewing over several days (Odenwald, 2006). Kassim and Croucher (2006), Griffiths (1998), Patel et al. (2005) and Nencini et al. (1984) observed amongst Yemeni and Somali khat chewers an increase in the amount of khat chewed among older and habitual khat chewers. Kassim and Croucher (2006) reported that more frequent chewing, i.e. chewing more than 2 days per week, was associated with psychological khat dependence although Eddy et al. (1965) has argued that the physical size and texture of khat bundle will naturally limit intake and thus prevent tolerance. The practice of refreshing the khat in the mouth during a long khat chewing session has been observed (Sawair et al., 2007; Kassim, 2010).

With respect to withdrawal symptoms, Alem et al. (1999) reported that chewers continued khat consumption to avoid unspecified symptoms, whilst chewers interviewed by Gelaw and Haile-Amlak (2004) reported that avoidance of unpleasant feelings and depression were the reasons to continue the behaviour. Specific khat related withdrawal symptoms are reported to include lethargy, nightmares (dokak, razem ${ }^{1}$ ), feeling hot in the lower extremities, continued urge to chew khat and slight trembling (Halbach, 1972; Luqman and Danowski, 1976; Kennedy and Hurwit, 1978; Al-Motarreb et al., 2002; Al-Habori, 2005). Smoking reductions, a behaviour often associated with khat chewing, may lead to irritability, sleep disturbance and depression (American Psychiatric Association, 2000) and should be taken into account as a possible confounder.

Gossop (2000) and Anderson et al. (2007) have proposed that a change in socio-cultural circumstances can have a powerful effect on drug use, including khat. In the past, in Yemen, khat chewing reportedly occurred only 2 days per week in the south of the country, whilst in the north it was chewed on a daily basis (Lenard

\footnotetext{
1 Dokak or Razem: These Arabic words describe the nightmares reported by chewers when stopping khat chewing, who perceive themselves as facing dangerous situations during sleep and being unable to shout or move.
}

and Al-Sabry, 1995). Khat chewing sessions in Yemen and Somalia are now held daily (Odenwald et al., 2009) complemented by the uptake of the behaviour by diverse social groups including school children and women (ACMD, 2005; Kebede et al., 2005; Odenwald et al., 2005; Patel et al., 2005; Bentur et al., 2008; Khawaja et al., 2008). Yemeni employed khat chewers settled elsewhere, such as the UK, are reported to chew over the weekend whilst the unemployed are more frequent chewers (Kassim and Croucher, 2006). Somali khat chewers reported that their khat chewing increased in the UK compared to Somalia (Griffiths, 1998). Nabuzoka and Badhadhe (2000) reported that though there were indications that whilst some continued chewing khat because they were dependent, most reported that they would rather associate themselves with the traditional socially acceptable Somali context of khat chewing.

The Severity of Dependence Scale (SDS) (Gossop et al., 1995) was initially developed to measure psychological dependence upon different drugs. Frequent application in international research has established the measure as a reliable, internally consistent, valid and culturally adaptable measure of problematic aspects of drug taking in the preceding 12 months (Gossop et al., 1995, 1997; Topp and Mattick, 1997; Ferri et al., 2000). The value of the SDS as a measure of psychological dependence arises from its comprehensibility, ease of administration and adaptation of its items to cover different drugs and different time frames through modifying the reference to the name of the drug under investigation. Additionally, the potential of SDS as a screening instrument lies in its ability to identify individuals with more likely problematic patterns of drug use within less than a minute compared with the DSM-IV 'gold standard' that requires more time and specific clinical training to assess individuals with drug dependence (Gossop et al., 1997; Topp and Mattick, 1997; Gossop, 2003).

There is no current consensus as to a measure of psychological khat dependence. Exploratory studies have used SDS (Kassim and Croucher, 2006; Griffiths et al., 1997) amongst UK Yemeni and Somali khat chewers. Establishing the generalisability of the SDS scale to khat chewing by assessing its validity, reliability and psychometric properties contributes to the ongoing process of scale development (Bowling, 1991). The relationship between a composite measure of khat chewing behaviour (Kassim, 2010) and psychological khat dependence also awaits exploration.

Therefore this study aimed (1) to assess psychological khat dependence and (2) to assess the validity and reliability of the Severity Dependence Scale (Gossop et al., 1995) amended for khat use, in a sample of UK-resident male adult Yemeni khat chewers. It was hypothesized that current khat chewing was not linked to khat dependency. We hypothesized that a specific pattern of khat chewing within the socio-cultural circumstance of living in the UK may lead to psychological dependence.

\section{Materials and methods}

\subsection{Study design and sample estimation}

This cross-sectional study recruited a purposive sample of male khat chewers, aged 18 years and above, selected during random visits to khat sellers. Men are reported to more likely be khat chewers (Numan, 2004; WorldBank, 2007). The sample size required for this study was estimated as 204. This calculation, using Epi-Info version 3.5, was based on previous estimates of prevalence khat chewing amongst Somali community reported by Bhui et al. (2003). The sample was drawn from the Sheffield Yemeni community estimated as approximately 4200 (Sheffield Hallam University, 2003), with 850 adult males over 19 years old. 


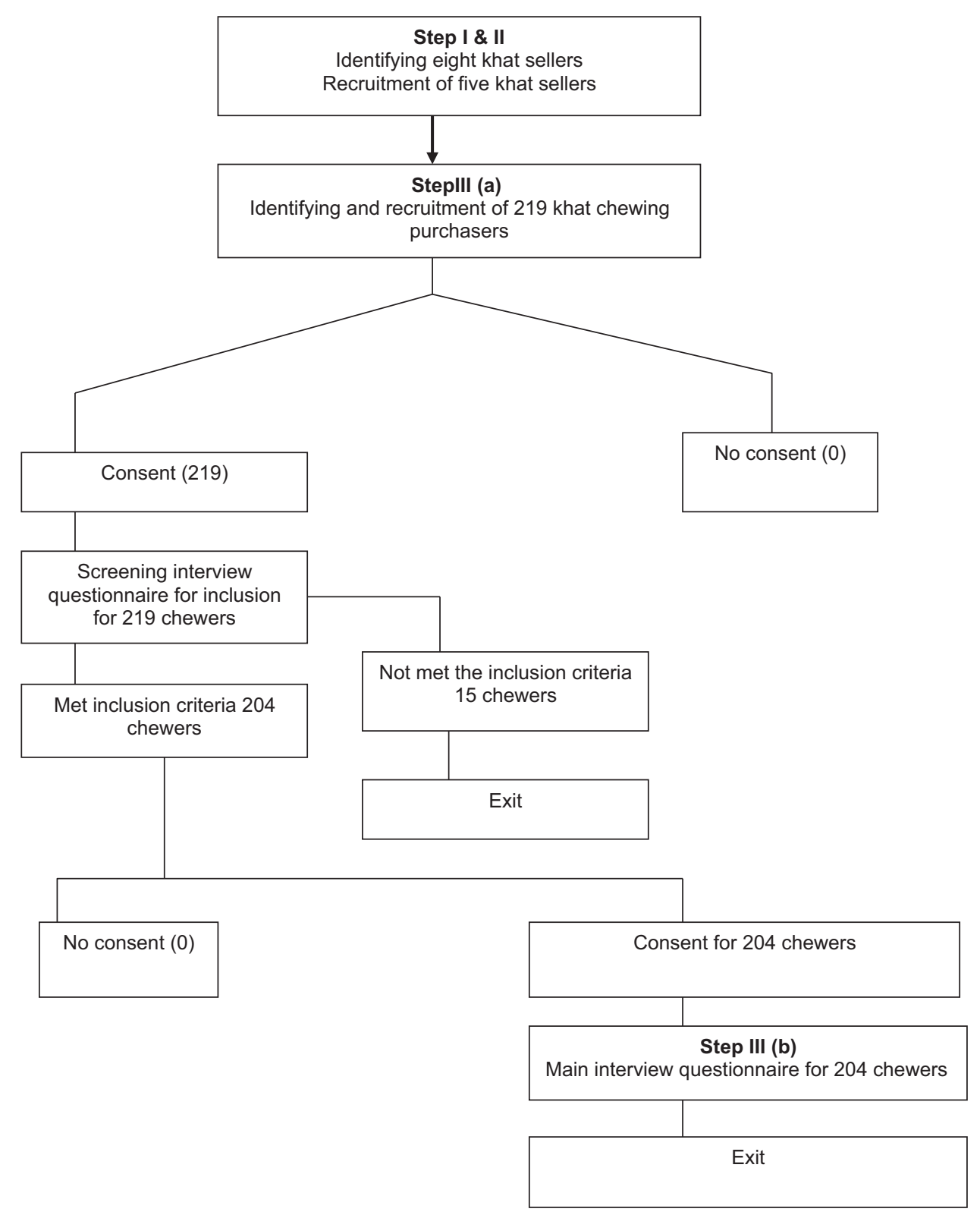

Fig. 1. Schematic of sample selection.

\subsection{Sample selection and characteristics}

Two hundred and four khat chewers were recruited from places of khat sale. Of these 124 were recruited in places where khat was both sold and chewed. The remainder was recruited in places selling khat alone (Fig. 1).

The mean age of respondents was 44.84 years $(S D \pm 19.70)$ and the range was $18-87$ years. Sixty five percent were unemployed and $66 \%$ had a low level of completed education achieved either in Yemen or UK. Ninety percent of respondents had either a social or private housing tenancy. A high percentage (73\%) of chewers was living in disadvantaged areas of Sheffield. Forty percent of respondents were born in villages that have been reported to cultivate khat in the Yemen.

The sample recruitment principles proposed by Taylor and Griffiths (2005) were followed. This proposed that in defining a drug using population, their physical and geographical sample point and, if necessary, a pre-specified time should be used instead of having a prior exhaustive sampling frame.
Three steps were undertaken to recruit the khat chewers (Fig. 1). Step I identified khat sellers: the geographic locations of khat sellers to the community were identified through social networking. Heads of the Yemeni community, gatekeepers in the Yemeni community and khat chewers were consulted. The names of khat sellers who agreed to participate and their locations were listed. Eight khat sellers were identified and five agreed to collaborate.

The second recruitment step involved the creation of a time table for visits for the five participating khat sale outlets. The time table, which randomly allocated visits to khat sellers and times for these visits, was developed using a random numbers table. As the activity of khat sale is started often at 1:00 pm-10:00 pm a decision to divide the day into two sessions $1.00 \mathrm{pm}-4.00 \mathrm{pm}$ and after $4.00 \mathrm{pm}$ was taken. This allowed the researcher to travel between outlets as well as to allow time for afternoon prayers as most of the Yemenis are Muslim.

A bilingual coloured poster describing the research was displayed in the khat sellers and Yemeni community' centers. Khat sellers were provided with the information sheet that explained the 
full study. This was then followed by the pre-specified recruitment visits.

The final recruitment step identified khat chewing purchasers and screened them for their eligibility to be recruited into the study. Chewers were approached and briefed about the study in the place of khat selling. Khat chewers who agreed to participate took part in the screening interview. Potential volunteers who met the inclusion criteria for the study were invited to take part in the main interview questionnaire.

The study included only adult Yemeni male khat chewers aged 18 years and over, who spoke Arabic or English, were currently resident in Sheffield, had regularly chewed khat (at least once weekly) over the preceding 12 months and were willing and capable to participate.

Occasional chewers and chewers with temporary residency (visitors, students) were excluded. The former were excluded on the basis of the drug dependence definition reported earlier (frequent use) and to avoid recall bias. Temporary residents were also excluded because of the study aim was to understand khat chewing in the particular context of the UK.

Khat chewers with linguistic barriers (not speaking English or Arabic) and with physical disability were not recruited due to a shortage of funding needed to interview the former and to ensure the health and safety for the latter. In addition, khat chewers with mental health problems and the terminally ill were excluded, as they were unable to give informed consent.

Potential volunteers who had agreed to participate in the main interview questionnaire were either interviewed at the khat sellers or given the opportunity to be interviewed later at a convenient time and place. Only one chewer was interviewed in his home. Confidentiality of the information that was obtained from chewers was assured throughout the interview.

The study was approved by East London and City Health Authority Local Research Ethics Committee. Informed written consent was obtained from participants.

Adaptation of sections of the screening interview questionnaire and the main interview questionnaire including the SDS-khat scale alongside the consent form and information sheet was carried out before the pilot study. The researcher followed the process of adaptation that was proposed by Hunt and Bhopal (2004), using four bilingual (English, Arabic) Yemeni khat chewers to forward translate into Arabic. Monolingual (Arabic speakers only) khat chewers were consulted during this process and field-testing was conducted. This then followed with back translation from Arabic to English. The researcher along with a Yemeni medical professional reviewed the translations (the professional was fully aware of khat culture among Yemeni community). The main interview questionnaire was piloted on a purposive sample of 20 Yemeni khat chewers.

\subsection{Measures}

A schedule interview questionnaire was developed for this study from previously piloted questions (Marin and Marin, 1991; Gossop et al., 1995; Griffiths, 1998; Kassim and Croucher, 2006; Croucher et al., 2007) alongside the validated measure of Fagerstorm Test of Nicotine Dependence (Heatherton et al., 1991). The demographic and socio-cultural characteristics assessed included age, marital status, level of education completed, current employment status, acculturation (language often spoken at home and work if employed and reading language preference) and level of their housing crowding. Social participation of chewers in their own community and the host community was also investigated. Different aspects of khat chewing that included age of starting the behaviour, number of days chewing in the week, reasons for chewing, attempts to stop khat chewing and the degree of psychological dependence on khat were asked.
The proposed SDS-khat consisted of five items to screen for psychological dependence over the last 12 months (Appendix A) (Arabic version available on request). The five items making up the proposed scale were: (1) Did you ever think that your khat chewing was out of control? (2) Did the prospect of not chewing any khat make you anxious or worried? (3) Did you worry about your khat chewing? (4) Did you wish you could stop chewing khat? and (5) How difficult would you find it to stop or go without khat chewing? Responses to four items were, 'Never or almost never', 'Sometimes', 'Often', 'Always or nearly always' and the fifth 'Not difficult', 'Quite difficult', 'Very difficult', 'Impossible'. Scores for each item ranged from 0 to 3 and the total score ranged from 0 to 15 .

Two amendments were made to the original SDS wording. Firstly, the fifth item was changed from the original wording of 'How did you find it to stop or go without chewing khat?' as many respondents had not attempted to stop chewing and therefore could not reflect on this experience. Secondly, as the Yemeni not only chew khat but rather chew and store it in the buccal cavity (Ali, 2005) the Yemeni term 'Takzeen' (Appendix A) was inserted into the English version to achieve the conceptual equivalence in Arabic.

Validation of varied cut off points using the 'gold standard' DSM-IV (1994) have been reported for different substances (Topp and Mattick, 1997; Kaye and Darke, 2002; Lawrinson et al., 2007; Gonzalez-Saiz et al., 2009). In this study, the distribution of SDSKhat was skewed (mean/SD 5.53 [ \pm 4.03 ], median 6.00). Therefore, the cut off point adopted was characterized these with $\leq 5$ scores as less probably dependent and $\geq 6$ scores as more probably dependents, reflecting the current literature (Altman, 1999; Streiner, 2002).

The reliability of the proposed scale was assessed using both test-retest and internal consistency scores. Fifteen khat chewers were selected randomly, i.e. one in ten and re-interviewed. Interviews of some chewers (5) were carried out on the same day of the main interview or within the following 3 consecutive days for chewers who were not available on the same day of the main interview, as the literature recommends (Gossop et al., 1997; Ferri et al., 2000; Norman and Streiner, 2000; Gossop, 2003).

\subsection{Statistical analysis}

The data were analysed using the SPSS software (Statistical Package of the Social Sciences, Version 16, SPSS Inc., and Chicago, IL, USA). Descriptive statistical analysis of the sample's characteristics and a psychometric properties of the proposed SDS-khat were undertaken.

Two steps were undertaken to validate the proposed scale. Exploratory rather than confirmatory factor analysis was adopted because of the absence in the current literature of studies of psychological dependence on khat chewing in any population of khat chewers (DeVellis, 2003).

The construct or factorial validity of this version of the SDS was assessed using the same techniques employed in assessing the psychometric properties of original version of SDS (Gossop et al., 1995). The data set was considered for suitability for factor analysis using conventional tests. These include the observation of values 0.6 or above for the Kaiser-Meyer-Olkin Test, the Test significance level $(p \leq 0.05)$ for Bartlett's Test of Sphericity and a correlation matrix of many coefficients of 3 and above. The factorability of the component proposed by the developers and the literature was compared to the results of this study sample. The eigenvalues of the components exceeding 1 and the variance explained were observed. The Catell's scree test that plots each of the factors against its associated eigenvalue was displayed.

The second step in validation was undertaken including assessment of the concurrent validity of the proposed SDS-khat. 
Concurrent validity is one of the aspects of criterion validity, in which the measure correlates with some other 'gold standard' measure of the trait or disorder under study (Streiner and Norman, 2003). Ten behavioural items related to khat chewing were explored using adapted items from Fagerstrom (1978) and items from previous studies of khat chewing (Griffiths, 1998; Kassim and Croucher, 2006). A composite index of khat behaviour was constructed from these items. These behaviours were first scored as 0 (absence) or 1 (presence) (Table 2). The range of these scores was $0-10$. According to the distribution it was then categorised into low ( $\leq 5$ scores) or high ( $\geq 6$ scores) composite index of khat behaviour. Simple logistic regression of the scale categories with both individual items and the composite index of khat behaviour was employed.

Additionally, self-reported reasons for khat chewing were correlated with SDS-khat categories. The internal consistency of the proposed scale was tested using Cronbach's alpha coefficient. Finally, preliminary analysis of response variation by language indicated no significant differences. Therefore, all the responses (162 in Arabic and 42 in English language) have been considered together.

This paper only reports data relating to the proposed SDS-khat.

\section{Results}

\subsection{Aspects of khat chewing}

The mean age of initiation of khat chewing was 18.53 years (SD \pm 5.48 ) and the range was 7-30 years. Seventy nine percent started khat chewing in Yemen. Ninety three percent of khat chewers preferred chewing Herari khat from Ethiopia and the rest chewed Mirra khat from Kenya, Yemeni khat or had no preference. Eighty percent, $19 \%$ and $94 \%$ respectively of respondents' fathers, mothers and current friends were khat chewers. Fifty four percent of respondents were introduced to khat chewing by friends and 35\% by family, family member, or during work on family khat land. Among the remainder (11\%), $8 \%$ reported that the availability of khat promoted self-initiation of khat chewing and the rest reported a belief in the medical benefits of khat chewing. The mean number of days per week spent in khat chewing was 2.95 days $(S D \pm 1.98)$. Fifty three percent of respondents reported chewing khat for 2 days or less and $14 \%$ chewed daily.

Forty six percent of respondents wanted to stop khat chewing. Of these $72 \%$ 'quite or very strongly' wanted to give up khat chewing. Forty eight percent of respondents had tried to stop khat chewing. The mean number of attempts was 3.77( $\mathrm{SD} \pm 3.55)$ and the range 1-20. Many factors were reported for chewing khat and this included social interaction (48\%), habit and dependence (21\%), help pass time (17.6\%), help concentration during work and study (5.9\%) and no alternative to khat chewing and isolation (4\%) and (3\%) respectively. Reported factors related to restarting chewing after cessation included, most commonly, isolation from own Yemeni community' (48.5\%), depression (15.5\%), dependence (8.2\%), avoiding alcohol (7.2\%), cannot study or work without khat (4.1\%), no alternative to khat chewing (6.2\%) and other reasons such as medical benefit (6.2\%) and helping to pass the time (4.1\%).

\subsection{Construct and concurrent validity of the proposed SDS-khat}

The mean score of the proposed SDS-khat was $5.52(\mathrm{SD} \pm 4.03)$ and the median was 6.00 (range $0.00-15.00$ ). Fourteen percent (14\%) of respondents scored zero, 35\% between 1 and 5 scores and the remainder six scores and more. More probably dependent respondents ( $\geq 6$ scores) accounted for $51 \%(95 \% \mathrm{CI}=45.00-57.00 \%$ ). Thirty two percent $(95 \% \mathrm{CI}=26.00-38.00 \%)$ of khat chewers scored 8 and above, suggesting a severe level of psychological dependence (Gossop et al., 1995).

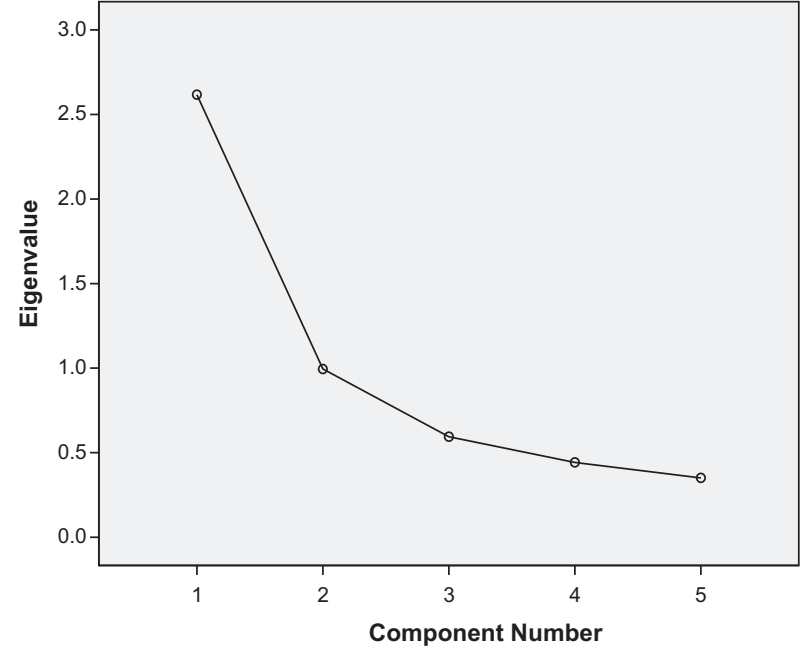

Fig. 2. SDS-khat scree plot.

The construct validity of the proposed SDS-khat was assessed using principal components analysis on the five SDS items. The data set yielded a correlation matrix of many coefficients of 0.3 and above as recommended by Tabachnick and Fidell (2001). The Kaiser-Meyer-Olkin Measure of Sampling Adequacy value was .758 , exceeding the recommended value of .6 (Kaiser, 1970, 1974). The Bartlett's Test of Sphericity (1954), was statistically significant (.005), supporting the factorability of the correlation matrix. A single-factor solution accounting for $52.33 \%$ of variance was obtained from factor analysis with principal components extraction of the five items comprising the SDS-khat, confirming the uni-dimensionality of the scale. Extraction of this factor was supported with the use of the Catell (1966) scree plot test (Fig. 2) which revealed a clear break after the first component.

The component matrix revealed that all the items loaded strongly (range 0.59-0.85) (Table 1 ) on this individual factor. The internal reliability of the proposed scale was high given the small number of items included in the scale (Cronbach's alpha coefficient $=0.76$ ). The test retest intraclass correlation coefficients (ICC) for the total scores was high $(0.93,95 \% \mathrm{CI} 0.80-0.97)$ and the correlation of each item with the total score (corrected item-total correlation) were $0.40-0.69$ (Table 1 ).

Many individual behaviours related to khat chewing were statistically significantly $(p \leq 0.05)$ associated with self-reported khat dependence (Table 2). More likely psychologically dependent respondents, measured by the proposed scale, were $14.40(95 \%$ $\mathrm{CI}=6.71-30.90)$ times more likely to have higher scores ( $\geq 6$ scores) of the composite index of khat chewing behaviour.

According to the SDS-khat, $73 \%$ of chewers who indicated that reasons for khat chewing were "being dependent", "habit" or "cannot work or study without khat chewing" scored $\geq 6$ scores. In contrast, $43 \%$ of respondents who indicated other reasons for khat chewing scored $\leq 5$. The differences were statistically significant $(p \leq 0.001, \mathrm{OR}=3.54 ; 95 \% \mathrm{CI}=1.80-6.96)$.

\section{Discussion}

Whether khat chewing creates psychological dependency or not is contested. Psychological dependency in khat chewers has only been preliminarily explored amongst UK resident Somali and Yemeni khat chewers (Griffiths et al., 1997; Kassim and Croucher, 2006). The Severity of Dependence Scale is recognized as a robust and adaptable measure of screening for dependence in diverse populations and samples. Frequency of khat chew- 
Table 1

Psychometric analysis of SDS with khat chewing (SDS-khat) in a sample of 204 UK resident Yemeni khat chewers.

\begin{tabular}{|c|c|}
\hline Variables & SDS-khat \\
\hline Mean $( \pm \mathrm{SD})$ & $5.52( \pm 4.03)$ \\
\hline Median & 6.00 \\
\hline Range & $0-15$ \\
\hline Number of factors & 1 \\
\hline \multicolumn{2}{|l|}{ Factor loading } \\
\hline $\begin{array}{l}\text { Item 1: Did you ever think that your khat chewing } \\
\text { (takzeen) was out of control? }\end{array}$ & 0.85 \\
\hline $\begin{array}{l}\text { Item 2: Did the prospect of not chewing any khat } \\
\text { (takzeen) make you anxious or worried? }\end{array}$ & 0.77 \\
\hline $\begin{array}{l}\text { Item 3: Did you worry about your khat chewing } \\
\text { (takzeen)? }\end{array}$ & 0.76 \\
\hline $\begin{array}{l}\text { Item 4: Did you wish you could stop chewing khat } \\
\text { (takzeen)? }\end{array}$ & 0.61 \\
\hline $\begin{array}{l}\text { Item 5: How difficult would you find it to stop or } \\
\text { go without khat chewing (takzeen)? }\end{array}$ & 0.59 \\
\hline \multicolumn{2}{|l|}{ Corrected item-total correlation } \\
\hline $\begin{array}{l}\text { Item 1: Did you ever think that your khat chewing } \\
\text { (takzeen) was out of control? }\end{array}$ & 0.69 \\
\hline $\begin{array}{l}\text { Item 2: Did the prospect of not chewing any khat } \\
\text { (takzeen) make you anxious or worried? }\end{array}$ & 0.57 \\
\hline $\begin{array}{l}\text { Item 3: Did you worry about your khat chewing } \\
\text { (takzeen)? }\end{array}$ & 0.43 \\
\hline $\begin{array}{l}\text { Item 4: Did you wish you could stop chewing khat } \\
\text { (takzeen)? }\end{array}$ & 0.44 \\
\hline $\begin{array}{l}\text { Item 5: How difficult would you find it to stop or } \\
\text { go without khat chewing (takzeen)? }\end{array}$ & 0.57 \\
\hline$\%$ Variance account for & $52.33 \%$ \\
\hline Cronbach's alpha coefficient & 0.76 \\
\hline Intraclass correlation coefficients (ICC) & 0.93 \\
\hline
\end{tabular}

ing was found to associate with psychological khat dependence (Kassim and Croucher, 2006) measured by SDS (Gossop et al., 1995).

The findings from this study support a SDS-khat scale as an instrument to screen for psychological dependence (Gossop et al., 1995, 1997; Ferri et al., 2000; Kaye and Darke, 2002; Lawrinson et al., 2007; Gonzalez-Saiz et al., 2009). The common features of drug dependence, such as compulsive use of the drug, were further supported (Drummond, 1991). Further exploration of this group of psychological dependent respondents in comparison with problematic patterns of use of other drugs such as nicotine, alcohol and areca nut is necessary.

The proposed scale has been found to have a good test-retest reliability and concurrent and construct validity in this sample of Yemeni khat chewers. The concurrent validity of the scale correlated with the behaviours of khat chewing. The study findings correlate with compulsive use, an important aspect of drug dependence (Nahas, 1981), as well as supporting the results of studies (Gossop et al., 1995; Ferri et al., 2000) which also explored links between the SDS scale with behavioural variables such as dose and frequency of taking drugs.

The findings from our study lend further support to the substantial literature that acknowledges the reliability and validity of self-report data from drug users (Babor and Brown, 1990). Statistically significantly associations $(p \leq 0.05)$ between self-reported 'drug dependence, habit and cannot work or study without khat chewing' were established with SDS-khat assessment as more probably dependent ( $\geq 6$ scores).

This study introduces a comprehensive list of individual behaviours relevant to Yemeni khat chewing and correlates them,

Table 2

Self-reported khat dependence and individual and composite khat chewing behaviours in a sample of 204 UK resident Yemeni khat chewers.

\begin{tabular}{|c|c|c|c|c|c|c|}
\hline \multirow[t]{2}{*}{ Khat chewing behaviour variables } & \multicolumn{6}{|c|}{ Severity of dependence on khat (SDS-khat) } \\
\hline & \multicolumn{2}{|c|}{$\begin{array}{l}\text { Less likely dependent ( } \leq 5 \\
\text { scores) } N(\%)\end{array}$} & \multicolumn{2}{|c|}{$\begin{array}{l}\text { More likely dependent ( } \geq 6 \\
\text { scores) } N(\%)\end{array}$} & \multirow[t]{2}{*}{ Unadjusted OR (95\% CI) } & \multirow[t]{2}{*}{$p$-Value } \\
\hline \multicolumn{5}{|l|}{ Setting of khat chewing } & & \\
\hline With others & 94 & $(53.7)$ & 81 & $(46.3)$ & 1 & \\
\hline By yourself & 6 & $(20.7)$ & 23 & $(79.3)$ & $4.45(1.73-11.46)$ & 0.001 \\
\hline \multicolumn{7}{|l|}{ Number of days chewing } \\
\hline 2 days or less & 75 & $(68.8)$ & 34 & $(31.2)$ & 1 & \\
\hline 3 days or more & 25 & $(26.3)$ & 70 & $(73.7)$ & $6.18(3.35-11.37)$ & 0.001 \\
\hline \multicolumn{7}{|l|}{ Time starting chewing } \\
\hline Between 3:00 pm and onward & 64 & $(57.1)$ & 48 & $(42.9)$ & 1 & \\
\hline Between 1.00 and $3.00 \mathrm{pm}$ & 36 & $(39.1)$ & 56 & $(60.9)$ & $2.07(1.83-3.64)$ & 0.011 \\
\hline \multicolumn{7}{|l|}{ Khat chewed in session } \\
\hline Up to 1 bundle & 70 & $(66.7)$ & 35 & $(33.3)$ & 1 & \\
\hline 1.25 bundle and more & 30 & $(30.3)$ & 69 & $(69.7)$ & $4.60(2.55-8.30)$ & 0.001 \\
\hline \multicolumn{7}{|l|}{12 prior months amount chewed } \\
\hline From lowest to 1 bundle & 71 & $(67.6)$ & 34 & $(32.4)$ & 1 & \\
\hline From 1.5 bundle to above & 29 & $(29.3)$ & 70 & $(70.7)$ & $5.04(2.78-9.14)$ & 0.001 \\
\hline \multicolumn{7}{|l|}{ Chewed more in first hours } \\
\hline No & 63 & $(64.9)$ & 34 & $(35.1)$ & 1 & \\
\hline Yes & 37 & $(34.6)$ & 70 & $(65.4)$ & $3.51(1.97-6.24)$ & 0.001 \\
\hline \multicolumn{7}{|l|}{ Khat chewing session hours } \\
\hline Up to $6 \mathrm{~h}$ & 72 & $(49.0)$ & 75 & $(51.0)$ & 1 & \\
\hline More than $6 \mathrm{~h}$ & 28 & $(49.1)$ & 29 & $(50.9)$ & $0.99(0.54-1.83)$ & 0.985 \\
\hline \multicolumn{7}{|l|}{ Chewing even ill } \\
\hline No & 77 & $(61.6)$ & 48 & $(38.4)$ & 1 & \\
\hline Yes & 23 & $(29.1)$ & 56 & $(70.9)$ & $3.91(2.13-7.15)$ & 0.001 \\
\hline \multicolumn{7}{|l|}{ Swallow khat juice } \\
\hline No & 9 & $(34.6)$ & 17 & $(65.4)$ & 1 & \\
\hline Yes & 91 & $(51.1)$ & 87 & $(48.9)$ & $0.51(0.21-1.19)$ & 0.117 \\
\hline \multicolumn{7}{|l|}{ Whole week not chewing } \\
\hline Very easy or fairly easy & 91 & $(75.8)$ & 29 & $(24.2)$ & 1 & \\
\hline Fairly difficult or very difficult & 9 & $(10.7)$ & 75 & $(89.3)$ & $26.15(11.66-58.65)$ & 0.001 \\
\hline \multicolumn{7}{|l|}{ Composite of khat behaviour } \\
\hline Low $(\leq 5$ scores $)$ & 90 & $(69.2)$ & 40 & $(30.8)$ & 1 & \\
\hline High ( $\geq 6$ scores) & 10 & $(13.5)$ & 64 & $(86.5)$ & $14.40(6.71-30.89)$ & 0.001 \\
\hline
\end{tabular}

Abbreviations: $\mathrm{CI}$, confidence interval, $p$, level of significance. 
alongside a composite measure of khat chewing behaviour, with SDS-khat.

The limitations of the study can be summarized as follows. Firstly, this is a cross-sectional study meaning that any causeeffect relationships should be excluded (Hill, 1965). In addition, the information was retrieved from participants through face to face interviews, potentially encouraging socially desirable responses (Bowling, 2009). Secondly, a majority of this study sample came from socially deprived backgrounds and was residing in a socially disadvantaged area. The social backgrounds of the study sample could have contributed to an overestimation of the community's khat dependence.

Furthermore, the exclusion of terminally ill chewers and chewers who may speak different languages than Arabic or English may affect the findings. Though none were identified during data collection, the requirements of the ethical committee approving the study have been taken into account in the case of the former and limited resources should be acknowledged in the case of the latter.

Finally, one of the important challenges that future research should address is to validate the proposed cut off point for SDSkhat in this study. Objective measures such as the khat metabolites norephedrine and pseudoephedrine (Nencini and Ahmed, 1989) offer a possible opportunity to address this gap in the knowledge alongside the proposed composite measure of khat behaviour. Likewise the relationship between aspects of khat behaviour, such as the number of khat bundles chewed in a session, with psychological dependency is an important area for future research (Warfa et al., 2007).

In conclusion, the proposed SDS-khat scale was found to provide strong evidence of its validity and reliability as a screening measure for khat chewing psychological dependence in this sample of UK-resident male adult Yemeni khat chewers. The composite khat chewing behaviour measure reported in this study should be tested amongst other minorities, such as women chewing different types of khat (Herari, Mirra and Yemeni) in different settings. This study is a starting point for further validation of the SDS-khat scale, particularly amongst Arabic speaking communities. The concurrent validation of the scale, using other metabolites of cathinone such as cathine and norephedrine in saliva, awaits development, alongside an evaluation of the scale's potential for clinical application.

\section{Acknowledgments}

We wish to acknowledge Professor Michael Gossop at King's College University in London and Dr. Mohamed Salam University of French-Comté in France for guidance during the process of adaptation of Severity of Dependency Scale. Support of the Yemeni community in Birmingham and Sheffield-UK is also acknowledged.

\section{Appendix A. Severity of dependence on khat (SDS-khat) (Gossop et al., 1995)}

In the last 12 months,

(1) Did you ever think that your khat chewing (takzeen) was out of control? Never or almost never Sometimes Often Always or nearly always

(2)Did the prospect of not chewing any khat (takzeen) make you anxious or worried? Never or almost never Sometimes Often Always or nearly always

(3) Did you worry about your khat chewing (takzeen)?

Never or almost never Sometimes Often Always or nearly always

(4) Did you wish you could stop chewing khat (takzeen)?

Never or almost never Sometimes Often Always or nearly always

(5) How difficult would you find it to stop or go without khat chewing (takzeen)? Not difficult

Quite difficult Very difficult Impossible

\section{References}

ACMD, 2005. Khat (Qat): assessment of risk to individual and communities in the UK. In: Advisory Council on the Misuse of Drugs (ACMD) (Eds.). British Home Office, London.

Aden, A., Dimba, E A, Ndolo, U.M. Chindia, M.L, 2006. Socio-economic effects of khat chewing in north eastern Kenya. East African Medical Journal 83, 69-73.

Alem, A., Kebede, D., Kullgren, G., 1999. The prevalence and socio-demographic correlates of khat chewing in Butajira, Ethiopia. Acta Psychiatrica Scandinavica. Supplementum 397, 84-91.

Altman, D.G., 1999. Practical Statistics for Medical Research. Chapman and Hall.

Al-Habori, M., 2005. The potential adverse effects of habitual use of Catha edulis (khat). Expert Opinion on Drug Safety 4, 1145-1154.

Ali, A., 2005. Comment on Oral white lesions associated with chewing khat. Tobacco Induced Diseases 3, 5-6.

Ali, A.A., 2007. Qat habit in Yemen society: a causative factor for oral periodontal diseases. International Journal of Environmental Research on Public Health 4 243-247.

Ali, A.A., Al-Sharabi, A.K., Aguirre, J.M., 2006. Histopathological changes in oral mucosa due to takhzeen al-qat: a study of 70 biopsies. Journal of Oral Pathology \& Medicine 35, 81-85.

Ali, A.A., Al-Sharabi, A.K., Aguirre, J.M., Nahas, R., 2004. A study of 342 oral keratotic white lesions induced by qat chewing among 2500 Yemeni. Journal of Oral Pathology \& Medicine 33, 368-372.

Al-Motarreb, A., Baker, K., Broadley, K.J., 2002. Khat: pharmacological and medical aspects and its social use in Yemen. Phytotherapy Research 16, 403-413.

Al-Motarreb, A., Briancon, S., Al-Jaber, N., Al-Adhi, B., Al-Jailani, F., Salek, M.S. Broadley, K.J., 2005. Khat chewing is a risk factor for acute myocardial infarction: a case-control study. British Journal of Clinical Pharmacology 59, 574-581.

American Psychiatric Association, 1994. Diagnostic and Statistical Manual of Mental Disorder: DSM-IV, fourth ed. Washington, DC

American Psychiatric Association, 2000. Diagnostic and Statistical Manual of Menta Disorders: DSM-IV-TR, fourth ed., text revision ed. Washington, DC.

Anderson, D., Beckerleg, S., Haillu, D., Klein, A., 2007. The Khat Controversy: Stimulating the Debate on Drugs. Oxford, Berg.

Babor, T.F., Brown, J., DelBoca, F.K., 1990. Validity of self reports in applied research on addictive behaviors: fact or fiction? Behavioral Assessment 12, 5-31.

Bartlett, M.S., 1954. A note on the multiplying factors for various Chi-square approximations. Journal of the Royal Statistical Society 16, 296-298.

Bentur, Y., Bloom-Krasik, A., Raikhlin-Eisenkraft, B., 2008. Illicit cathinone ("Hagigat") poisoning. Clinical Toxicology (Philadelphia) 46, 206-210.

Bhui, K., Abdi, A., Abdi, M., Pereira, S., Dualeh, M., Robertson, D., Sathyamoorthy G., Ismail, H., 2003. Traumatic events, migration characteristics and psychiatric symptoms among Somali refugees - preliminary communication. Social Psychiatry and Psychiatric Epidemiology 38, 35-43.

Bowling, A., 1991. Measuring Health: A Review of Quality of Life Measurement Scales. Open University Press, Milton Keynes.

Bowling, A., 2009. Research Methods in Health: Investigating Health and Health Services. Open University Press, Maidenhead.

Catell, R.B., 1966. The scree test for number of factors. Multivariate Behavioral Research 1, 245-276.

Churchill, A.C., Burgess, P.M., Pead, J., Gill, T., 1993. Measurement of the severity of amphetamine dependence. Addiction 88, 1335-1340.

Croucher, R.E., Islam, S.S., Pau, A.K., 2007. Concurrent tobacco use in a random sample of UK-resident Bangladeshi men. Journal of Public Health Dentistry 67, 83-88.

DeVellis, R.F., 2003. Scale Development: Theory and Applications. Sage, Thousand Oaks, Calif., London.

Dhaifalah, I., Santavy, J., 2004. Khat habit and its health effect. A natural amphetamine. Biomedical Papers of the Medical Faculty of the University Palacky, Olomouc, Czechoslovakia 148, 11-15.

Drummond, C., 1991. Dependence on psychoactive drugs: findings a common language. In: Glass, I.B. (Ed.), The International Handbook of Addiction Behavior. Tavistock/Routledge, London (Chapter 1).

Eddy, N.B., Halbach, H., Isbell, H., Seevers, M.H., 1965. Drug dependence: its significance and characteristics. Bulletin of the World Health Organization 32 721-733.

Edwards, G., Gross, M.M., 1976. Alcohol dependence: provisional description of a clinical syndrome. British Medical Journal 1, 1058-1061.

Edwards, G., Arif, A., Hodgson, R., 1981. Nomenclature and classification of drug- and alcohol-related problems: a WHO Memorandum. Bulletin of the World Health Organization 59, 225-242.

Fagerstrom, K.O., 1978. Measuring degree of physical dependence to tobacco smoking with reference to individualization of treatment. Addictive Behaviors 3 235-241.

Food and Agriculture Organization of the United Nations, 2008. Qat Production in Yemen: Water Use, Competitiveness and Possible Policy Options for Change. Regional Office for the Near East, Cairo, Egypt.

Ferri, C., De AraujoM, M.J., Laranjeira, R.R., Gossop, M., 2000. The Severity of Dependence Scale (SDS) in an adolescent population of cannabis users: reliability, validity and diagnostic cut-off. Drug and Alcohol Review 19, 451-455.

Feyissa, A.M., Kelly, J.P., 2008. A review of the neuropharmacological properties of khat. Progress in Neuro-psychopharmacology \& Biological Psychiatry 32, 1147-1166.

Freund-Michel, V.C., Birrell, M.A., Patel, H.J., Murray-Lyon, I.M., Belvisi, M.G., 2008 Modulation of cholinergic contractions of airway smooth muscle by cathinone: 
potential beneficial effects in airway diseases. The European Respiratory Journal 32, 579-584.

Gawin, F.H., Kleber, H.D., 1986. Abstinence symptomatology and psychiatric diagnosis in cocaine abusers. Archives of General Psychiatry 43, 107-113.

Gelaw, Y., Haile-Amlak, A., 2004. Khat chewing and its socio-demographic correlates among the staff of Jimma University. Ethiopian Journal of Health and Development 18, 179-184.

Gelaye, B., Philpart, M., Goshu, M., Berhane, Y., Fitzpatrick, A.L., Williams, M.A., 2008 Anger expression, negative life events and violent behaviour among male college students in Ethiopia. Scandinavian Journal of Public Health 36, 538-545.

Gonzalez-Saiz, F., Domingo-Salvany, A., Barrio, G., Sanchez-Niubo, A., Brugal, M.T., de la Fuente, L., Alonso, J., 2009. Severity of dependence scale as a diagnostic tool for heroin and cocaine dependence. European Addiction Research 15, 87-93.

Gossop, M., 2000. Living with Drugs. Ashgate, Brookfield, Vt.

Gossop, M., 2003. Drug Addiction and Its Treatment. Oxford University Press, Oxford.

Gossop, M., Best, D., Marsden, J., Strang, J., 1997. Test-retest reliability of the severity of dependence scale. Addiction 92, 353.

Gossop, M.R., Bradley, B.P., Brewis, R.K., 1982. Amphetamine withdrawal and sleep disturbance. Drug and Alcohol Dependence 10, 177-183.

Gossop, M., Darke, S., Griffiths, P., Hando, J., Powis, B., Hall, W., Strang, J., 1995 The Severity of Dependence Scale (SDS): psychometric properties of the SDS in English and Australian samples of heroin, cocaine and amphetamine users. Addiction 90, 607-614.

Griffiths, P., 1998. Qat Use in London: a Study of Qat Use Among a Sample of Somalis Living in London. (Bd. Paper 26). Home Office, London.

Griffiths, P., Gossop, M., Wickenden, S., Dunworth, J., Harris, K., Lloyd, C., 1997. A transcultural pattern of drug use: qat (khat) in the UK. The British Journal of Psychiatry 170, 281-284.

Halbach, H., 1972. Medical aspects of the chewing of khat leaves. Bulletin of the World Health Organization 47, 21-29.

Hassan, N.A., Gunaid, A.A., El Khally, F.M., Murray-Lyon, I.M., 2002. The subjective effects of chewing Qat leaves in human volunteers. Annals of Saudi Medicine 22, 34-37.

Heatherton, T.F., Kozlowski, L.T., Frecker, R.C., Fagerstrom, K.O., 1991. The Fagerstrom test for nicotine dependence: a revision of the Fagerstrom tolerance questionnaire. British Journal on Addictions 86, 1119-1127.

Hill, A.B., 1965. The environment and disease: association or causation? Proceedings of the Royal Society of Medicine 58, 295-300.

Hunt, S.M., Bhopal, R., 2004. Self report in clinical and epidemiological studies with non-English speakers: the challenge of language and culture. Journal of Epidemiology and Community Health 58, 618-622.

Kaiser, H., 1970. A second generation Little Jiffy. Psycometrika 35, 401-415.

Kaiser, H., 1974. An index of factorial simplicity. Psychometrika 39, 31-36.

Kalix, P., 1982. The amphetamine-like releasing effect of the alkaloid (-)cathinone on rat nucleus accumbens and rabbit caudate nucleus. Progress in Neuropsychopharmacology \& Biological Psychiatry 6, 43-49.

Kalix, P., 1990. Pharmacological properties of the stimulant khat. Pharmacology \& Therapeutics 48, 397-416.

Kalix, P., Braenden, O., 1985. Pharmacological aspects of the chewing of khat leaves. Pharmacological Reviews 37, 149-164.

Kassim, S., 2010. An exploration of the association between khat chewing and health outcomes in UK-residents male Yemeni khat chewers. Ph.D. thesis, Queen Mary University of London.

Kassim, S., Croucher, R., 2006. Khat chewing amongst UK resident male Yemeni adults: an exploratory study. International Dental Journal 56, 97-101.

Kaye, S., Darke, S., 2002. Determining a diagnostic cut-off on the Severity of Dependence Scale (SDS) for cocaine dependence. Addiction 97, 727-731.

Kebede, D., Alem, A., Mitike, G., Enquselassie, F., Berhane, F., Abebe, Y., Ayele, R., Lemma, W., Assefa, T., Gebremichael, T., 2005. Khat and alcohol use and risky sex behaviour among in-school and out-of-school youth in Ethiopia. BMC Public Health 5, 109.

Kennedy, J., Hurwit, R., 1978. Qat's cradle. Human Behavior (October), 38-39.

Khawaja, M., Al-Nsour, M., Saad, G., 2008. Khat (Catha edulis) chewing during pregnancy in Yemen: findings from a national population survey. Maternal and Child Health Journal 12, 308-312.

Krikorian, A., 1984. Khat and its use: an historical perspective. Journal of Ethnopharmacology 12, 115-178.

Lawrinson, P., Copeland, J., Gerber, S., Gilmour, S., 2007. Determining a cut-off on the Severity of Dependence Scale (SDS) for alcohol dependence. Addictive Behaviors 32, 1474-1479.

Lenard, M., Al-Sabry, M., 1995. The Rational peasant vs. sustainable livelihood: the case of Qat in Yemen. Society for International Development, 3.
Luqman, W., Danowski, T.S., 1976. The use of khat (Catha edulis) in Yemen. Social and medical observations. Annals of Internal Medicine 85, 246-249.

Marin, G., Marin, B.V., 1991. Research with Hispanic Population. Applied Social Research Methods Series, vol. 23. Sage Publication, Inc., Newbury Park, CA.

Nabuzoka, D., Badhadhe, F., 2000. Use and perception of khat among young Somalis in a UK city. Addiction Research 8, 5-26.

Nahas, G.G., 1981. A pharmacological classification of drugs of abuse. Bulletin on Narcotics 33, 1-19.

Nencini, P., Grassi, M.C., Botan, A.A., Asseyr, A.F., Paroli, E., 1989. Khat chewing spread to the Somali community in Rome. Drug and Alcohol Dependence 23, 255-258.

Nencini, P., Ahmed, A.M., 1989. Khat consumption: a pharmacological review. Drug and Alcohol Dependence 23, 19-29.

Nencini, P., Ahmed, A.M., Amiconi, G., Elmi, A.S., 1984. Tolerance develops to sympathetic effects of khat in humans. Pharmacology 28, 150-154.

Norman, G.R., Streiner, D.L., 2000. Biostatistics: The Bare Essentials. B. C. Decker, Hamilton.

Numan, N., 2004. Exploration of adverse psychological symptoms in Yemeni khat users by the Symptoms Checklist-90 (SCL-90). Addiction 99, 61-65.

Odenwald, M., 2006. The use of the stimulant khat, war-related trauma and psychosis in Somalia. How changed use patterns of a traditional drug are related to psychiatric problems in a country in the transition from war to peace. Universität Konstanz. Dissertation zur Erlangung des Doktorgrades. http://deposit.ddb.de/cgi-bin/dokserv?idn=983478139\&dok_var=d1\&dok_ext= pdf\&filename=983478139.pdf (accessed on 20.10.08).

Odenwald, M., 2009. Motivations for using khat. In: European Science Foundation (ESF). The Changing Use and Misuse of Catha Edulis (Khat) in a Changing World: Tradition, Trade and Tragedy. Scandic Linkoping Vast, Linkoping, 5-9, October, Swede.

Odenwald, M., Neuner, F., Schauer, M., Elbert, T., Catani, C., Lingenfelder, B., Hinkel, H., Hafner, H., Rockstroh, B., 2005. Khat use as risk factor for psychotic disorders: a cross-sectional and case-control study in Somalia. BMC Med 3, 5.

Odenwald, M., Warfa, N., Bhui, K., Elbert, T., 2009. The stimulant khat-another door in the wall? A call for overcoming the barriers. Journal of Ethnopharmacology.

Patel, S., Wright, S., Gammampila, A., 2005. Khat use among Somalis in four English cities (Bd. Home Office Online Report 47/05). Home Office.

Rousseau, C., Said, T.M., Gagne, M.J., Bibeau, G., 1998. Between myth and madness: the premigration dream of leaving among young Somali refugees. Culture, Medicine and Psychiatry 22, 385-411.

Sawair, F.A., Al-Mutwakel, A., Al-Eryani, K., Al-Surhy, A., Maruyama, S., Cheng, J., Al-Sharabi, A., Saku, T., 2007. High relative frequency of oral squamous cell carcinoma in Yemen: qat and tobacco chewing as its aetiological background. International Journal of Environmental Health Research 17, 185-195.

Sheffield Hallam University, 2003. Yemeni Community Survey in Sheffield, UK.

Streiner, D.L., 2002. Breaking up is hard to do: the heartbreak of dichotomizing continuous data. Canadian Journal of Psychiatry 47, 262-266.

Streiner, D.L., Norman, G.R., 2003. Health Measurement Scales: a Practical Guide to Their Development and Use. Oxford University Press, Oxford.

Tabachnick, B.G., Fidell, L.S., 2001. Using Multivariate Statistics. Allyn and Bacon, Boston, Mass, London.

Taylor, C., Griffiths, P., 2005. Sampling issues in drug epidemiology. In: Sloboda, Z. (Ed.), Epidemiology of Drug Abuse. Springer Press, pp. 80-90.

Toennes, S.W., Harder, S., Schramm, M., Niess, C., Kauert, G.F., 2003. Pharmacokinetics of cathinone, cathine and norephedrine after the chewing of khat leaves. British Journal of Clinical Pharmacology 56, 125-130.

Topp, L., Darke, S., 1997. The applicability of the dependence syndrome to amphetamine. Drug and Alcohol Dependence 48, 113-118.

Topp, L., Mattick, R.P., 1997. Choosing a cut-off on the Severity of Dependence Scale (SDS) for amphetamine users. Addiction 92, 839-845.

Warfa, N., Klein, A., Bhui, K., Leavey, G., Craig, T., Alfred Stansfeld, S., 2007. Khat use and mental illness: a critical review. Social Science \& Medicine 65, 309-318.

WHO, 2003. Expert Committee on Drug Dependence. World Health Organ Tech Rep Ser 915, i-v, 1-26, back cover

WHO, 2006. WHO Expert Committee on Drug Dependence. World Health Organ Tech Rep Ser, i, 1-21, 23-24 passim.

Woolverton, W.L., Johanson, C.E., 1984. Preference in rhesus monkeys given a choice between cocaine and D,L-cathinone. Journal of the Experimental Analysis of Behavior 41, 35-43.

WorldBank, 2007. Yemen towards Qat demand reduction. Report No. 39738-YE.

Zein, Z.A., 1988. Polydrug abuse among Ethiopian university students with particular reference to khat (Catha edulis). Journal of Tropical Medicine and Hygiene 91, 71-75. 